\title{
Title: Silver integrated with carbonaceous 2D nanomaterials as an electrocatalyst for reductive dechlorination of chloroacetanilide herbicide
}

\author{
Author Names: Jaroslav Filip ${ }^{1 z}$, Stepan Vinter ${ }^{1}$, Pavel Skacelik ${ }^{1}$, Jitka Sotolarova ${ }^{1}$, Katarina \\ Borska $^{2}$, Josef Osicka ${ }^{3}$ \\ Affiliation(s): \\ ${ }^{1}$ Department of Environmental Protection Engineering, Faculty of Technology, Tomas Bata \\ University in Zlin, Vavreckova 275, 76001 Zlin, Czech Republic \\ 2 Polymer Institute of the Slovak Academy of Sciences, Dubravska cesta 9, 84541 Bratislava, \\ Slovakia \\ ${ }^{3}$ Centre of Polymer Systems, Tomas Bata University in Zlín, Třída Tomáše Bati 5678, 76001 \\ Zlín, Czech Republic \\ ${ }^{z}$ Corresponding author's (J. Filip) email address: jfilip@utb.cz
}

\begin{abstract}
In this work silver nanoparticles (AgNPs) were in-situ synthesized on surface of graphene oxide (GO) and $\mathrm{Ti}_{3} \mathrm{C}_{2} \mathrm{~T}_{\mathrm{X}} \mathrm{MXene}$ at room temperature and without any reducing agent. The prepared GO_AgNPs and MX_AgNPs nanomaterials were deposited on electrodes and applied for voltammetric sensing of pesticide metazachlor. The chosen analyte underwent electrochemical reduction readable as faradaic current and identified as the electrochemical reductive dechlorination. It was found that GO_AgNP (electrochemically reduced to ErGO_AgNP before measurements) was more efficient catalyst of the observed dechlorination than MX_AgNP, even though it contained approximately 10-fold lower amount of silver. The smaller size of AgNP achieved with GO was the most probable reason. When the metazachlor sensing properties of the nanohybrid-modified electrodes were investigated, the linear range and the limit of detection of $37-1123 \mu \mathrm{M}$ and $27 \mu \mathrm{M}$, respectively, were observed for ErGO_AgNP while only $37-375 \mu \mathrm{M}$ and $40 \mu \mathrm{M}$ for MX_AgNP. The ErGO_AgNP nanohybrid was more convenient also for metazachlor detection in alkali leachate of real soil samples, probably as the result of antifouling effect of ErGO. Although there are conventional instrumental analysis methods for sensing orders of magnitude lower concentrations of metazachlor, in this work it is for the first time shown that the AgNP-based nanohybrid efficiently catalyse the electrochemical dechlorination applicable for detection of this frequently used pesticide.
\end{abstract}

\section{Introduction}

Intensive agriculture is inevitably connected to application of herbicides which are often compounds raising concerns about their adverse health effect and impact on environment. It makes pressure on analytical methods for determination of pesticides with typical analytical tools including chromatographic methods (liquid chromatography, gas chromatography) mass spectroscopy and so on ${ }^{1}$. They are mostly recognized as "high-performance" but the higher the performance, the higher the instrument price. Furthermore, these methods typically require trained operators and cannot be performed outdoor. These drawbacks are overcome by methods 
of electrochemical analysis, which employs versatile, easy-to-operate, sensitive and compact/portable devices at low prices. The sufficiency of electrochemical methods for determination of pesticides can be proved for example by a number of studies listed in both older and recent reviews covering different aspects of electrochemical sensing and biosensing of pesticides ${ }^{1-8}$.

Metazachlor (2-chloro-N-(pyrazol-1-ylmethyl)acet-2',6'-xylidide) is a recently widely used chloroacetanilide herbicide applied mainly on rapeseed and ornamental trees ${ }^{9}$. It is considered low to moderately persistent but its transformation products - metazachlor ESA (ehtylsulfonic acid) or metazachlor OA (oxalic acid) exhibit higher persistency and may be found in different environment compartments ${ }^{10,11}$, even several months after their application ${ }^{12}$. Since it exhibits moderate toxicity to some aqueous organisms ${ }^{12}$ and due to other potential health risks ${ }^{9}$, it is desirable to have handy analytical tool for metazachlor determination. Many data suggested that electrochemical oxidative ${ }^{13}$ or reductive cleavage of C-Cl bond in chloroacetanilide structures is possible at feasible potentials in non-aqueous ${ }^{14}$ or aqueous ${ }^{15-17}$ environment with different catalysts including silver electrodes promoting this reaction ${ }^{18-20}$ due to the strong affinity of $\mathrm{Cl}$ to silver (see also a current review ${ }^{21}$ and references therein). Such process was employed also for electrochemical sensing of alachlor using dropping mercury electrode ${ }^{22}$. Ajermoun et al. reported the enhanced electrochemical reduction of imidacloprid (Cl- containing neonicotinamide pesticide) when silver was integrated with a metallic electrode. They concluded that silver decreased an activation energy, allowing for better electrochemical behavior of imidaclopride over electrodes without the integrated silver ${ }^{23}$, but the authors have not claimed that the dechlorination has occurred. To complete the list, it should be noted that the oxidation of chloroacetanilide herbicides on boron-doped diamond electrode was also the identified mechanism employed for their electrochemical determination 24, 25. Silver nanoparticles synthesized on Ni foam and their efficient employment in a bulk electrochemical dechlorination of the chloracetoanilide alachlor were reported ${ }^{20,26-28}$, but without its electrochemical detection. Similarly, silver nanoparticles were synthesized on glassy carbon electrodes and employed for reductive electrodechlorination of chloroacetic acids (CA) in a few studies ${ }^{29,30}$, some of them also investigated dependence of a cathodic (dechlorination) peak height on CA concentration $(0-20 \mathrm{mM})$ and found it to be linear ${ }^{31}$. These studies have in common two features. First, the described electrodes with silver nanoparticles were employed only for bulk dechlorination, not for concentration determination. The other is a conclusion that the proposed dechlorination mechanism rely on $\mathrm{H}$ atoms released from water and their deposition on the active electrode surface ${ }^{29}$, 30, what advocates for employment of nanostructures with a large active surface area. From the facts given in this paragraph it could be assumed that i) silver nanoparticles introduced on an electrode surface should increase a rate of electrocatalytic dechlorination of metazachlor and ii) it could be employable in electrochemical detection of metazachlor.

"MXene" is a general name for layered, 2D carbides, nitrides or carbonitrides of transition metals ${ }^{32-36}$. In 2011, there appeared the first report on their preparation by etching of $\mathrm{Al}$ atoms from otherwise 3D "MAX" phase where "M" denotes transition metal (Ti, W, Mo...), " $\mathrm{X}$ " is $\mathrm{C}$ or $\mathrm{N}$ element and " $\mathrm{A}$ " is the $\mathrm{Al}$ content which has been removed by $\mathrm{HF}^{34}$. MXenes' inherent electrochemical activity imposed by transition metal atoms together with 
their nanostructure (that is, large active surface area), allows for their application in sensing and biosensig ${ }^{37-42}$, including detection of benzimidazol fungicides ${ }^{43-45}$. Besides the unmodified MXene, there are also examples of metal nanoparticles synthesized in-situ on the MXene surface. Zero-valent $\mathrm{Ti}$ atoms in the MXene structure can be oxidized at a redox potential above $400 \mathrm{mV}$ (vs. $\mathrm{Ag} / \mathrm{AgCl}$ electrode) ${ }^{46}$ while the reduction of different oxidized metal species $\left(\mathrm{M}^{\mathrm{n}+}\right)$ can occur at significantly lower potentials ${ }^{47}$. Difference between those values is the driving mechanism for the spontaneous deposition of reduced metal $\mathrm{M}(0)$ atoms on MXenes. The latter is, at the same time, oxidized to MXene with $\mathrm{Ti}_{X} \mathrm{O}_{Y}$ structures. Using this mechanism MXene grafted with Au, Pd and Pt-containing ${ }^{48,49}$, silver ${ }^{50}$ or platinum ${ }^{46,51}$ nanoparticles were prepared. These nanomaterials promote the electrocatalytic properties which can be employed for energy-related reactions (hydrogen evolution reaction, oxygen reduction...) ${ }^{51-53}$, detection of small molecules ${ }^{46}$ and also for biosensing of organophosphate pesticides ${ }^{48}$, but recently there are not any reports on metal nanoparticles/MXene hybrids employed for direct electrochemical sensing of pesticides.

Another popular 2D nanomaterial with a great potential in pesticide (bio)sensing is graphene and its derivatives ${ }^{49}$. While the former exhibit excellent electron conductivity, very high flexibility and strength but also hydrophobicity, the latter, including graphene oxide (GO) is hydrophilic (i.e. easily handled in aqueous dispersions), non-conductive and bears oxygen moieties (carboxyls, carbonyls, hydroxyls...) which are readily available for chemical modifications. They can also attach positively charged metal ions, which is known to promote the rate of in-situ metal nanoparticle synthesis. In fact, graphene oxide has been also determined as the possible agent for reduction of metal ions, as investigated in our previous study ${ }^{54}$ and elsewhere. Therefore, similarly to MXene-metal nanoparticles nanohybrides, graphene oxide has been also employed for synthesis of GO-metal nanoparticles hybrid nanomaterials which exhibited good electrocatalytic properties. Examples include $\mathrm{Au}$ nanoparticles decorated GO employed for determination of chloramphenicol (no dechlorination, but reduction of nitro- group observed) ${ }^{55}$, $\mathrm{Pd} / \mathrm{GO} / \mathrm{Ti}$ nanohybrid employed for electrodegradation of 2,4-dichlorophenol ${ }^{56}$ or GO-Ag nanoparticles for detection of hydrogen peroxide ${ }^{57}$. Furthermore, in our previous study it was found that silver nanoparticles deposited on the surface of electrochemically reduced graphene oxide can provide electrochemical signal related to metazachlor dechlorination, but without a focus on its quantitative determination ${ }^{54}$.

In this work, electrochemical behavior of widely used herbicide metazachlor was investigated using silver nanoparticles synthesized by facile "self-reduction" methods on two types of $2 \mathrm{D}$ nanomaterial supports, i.e. graphene oxide and $\mathrm{Ti}_{3} \mathrm{C}_{2} \mathrm{~T}_{\mathrm{X}}$ MXene. Both nanomaterials were capable to promote metazachlor dechlorination only in presence of integrated silver nanoparticles and the observed voltammetric response could be quantitatively correlated to the metazachlor concentration establishing the base for fabricating electrochemical metazachlor sensor.

\section{Experimental}

Reagents

Graphene oxide (GO; aqueous dispersion $4 \mathrm{mg} \mathrm{mL}^{-1}$, Graphene Laboratories Inc., 
USA); silver nitrate (Lachema, Czech republic); metazachlor (MZCh) (Chemos, Czech republic); sodium hydroxide (Penta, Czech Republic); Ti 2 AlC powder (Kanthal, Sweden); TiC (Sigma-Aldrich, nanopowder, $<200 \mathrm{~nm}$ ); hydrofluoric acid (Sigma-Aldrich). All aqueous solutions were prepared using deionized water (DW).

\section{MXene preparation}

MXene preparation consisted of two steps. 1) Synthesis of $\mathrm{Ti}_{3} \mathrm{AlC}_{2}$ (MAX phase) was performed according to ${ }^{32}$ by mixing commercial $\mathrm{Ti}_{2} \mathrm{AlC}$ with $\mathrm{TiC}$ in a $1: 1$ molar ratio followed by ball milling for $18 \mathrm{~h}$ and heating at $5{ }^{\circ} \mathrm{C} \mathrm{min}^{-1}$, under flowing argon (Ar) in a tube furnace for $2 \mathrm{~h}$ at $1350^{\circ} \mathrm{C}$. 2) Next step was performed according to protocol published in ${ }^{34}$ : the prepared MAX phase powder was immersed in 50\% aqueous HF solution (1 g for $10 \mathrm{~mL}$ of HF solution) for 2 hours with magnetic stirring. The suspension was then diluted with deionized water and centrifuged and washed repeatedly until the $\mathrm{pH}$ of supernatant was neutral. The produced powder was dried at $35^{\circ} \mathrm{C}$ at low vacuum over 24 hours. It was followed by delamination performed by stirring in DMSO solution and $4 \mathrm{~h}$ sonication ${ }^{58}$ followed by drying.

\section{Synthesis of $M X \_A g N P$ and $G O \_A g N P$}

For MX_AgNP synthesis the protocol published in ${ }^{59}$ was employed. $100 \mathrm{mg}$ of the prepared $\mathrm{Ti}_{3} \mathrm{C}_{2} \mathrm{~T}_{\mathrm{X}}$ MXene was mixed with $80 \mathrm{ml}$ of deionized water (DW) and treated in ultrasonic bath for $30 \mathrm{~min}$ to obtain homogeneous dispersion. After that, $20 \mathrm{~mL}$ of $14.7 \mathrm{mM}$ aqueous solution of $\mathrm{AgNO}_{3}$ was slowly added into the stirred MXene dispersion and the intensive stirring continued for the whole incubation time. Three incubation times were tested, that is, $10 \mathrm{~min}, 2 \mathrm{~h}$ and $24 \mathrm{~h}$. When incubation was finished, centrifugation (30 min, 11500 RPM) was employed to separate solid and liquid phase. The precipitate was than centrifuged with absolute ethanol two times. The final product was left to dry out at $55^{\circ} \mathrm{C}$. It was labelled as MX_AgNP and, if necessary, incubation times are distinguished by using labels MX_AgNP10, MX_AgNP2 and MX_AgNP24 for incubation time $10 \mathrm{~min}, 2 \mathrm{~h}$ and $24 \mathrm{~h}$, respectively.

GO_AgNP was prepared as follows: $200 \mu \mathrm{L}$ of GO dispersion was mixed with $15.5 \mathrm{~mL}$ of $\mathrm{DW}$ and $10 \mathrm{~mL}$ of $1 \mathrm{mM} \mathrm{AgNO} 3$ was slowly added during intensive stirring. The mixture was stirred and incubated for 2 hours, followed by solid phase separation from the liquid by centrifugation (30 min, 11500 RPM) and decantation of the supernatant. The precipitate was resuspended in DW and the centrifuge separation was repeated. Total number of these washing cycles was 3 and final product (precipitate left after the final centrifugation) was resuspended in $200 \mu \mathrm{L}$ of GO and this dispersion was denoted to as GO_AgNP.

\section{Electrode modification}

GCE electrodes $\left(0.0707 \mathrm{~cm}^{2}\right.$, BASi, USA) were first precleaned by mechanical polishing on wetted polishing pad (Microcloth, Buehler, USA) to remove any visually detectable remnants and after intensive rinse in DW they were mechanically polished using alumina polishing paste (MicroPolish Alumina $0.3 \mu \mathrm{m}$, Buehler, USA) for $3 \mathrm{~min}$. It was followed by rinse with DW and 1 min cleaning in DW using ultrasound bath and again rinse with DW. After a fast drying by a nitrogen or air stream, the electrodes were ready for 
modification. It was performed by pipetting of $10 \mu \mathrm{L}$ of the GO_AgNP dispersion and letting to dry out at a nitrogen stream. These electrodes were consequently reduced using cyclic voltammetry (-1.5 to $0 \mathrm{~V}, 25$ scans, $100 \mathrm{mV} \mathrm{s}^{-1}$ scan rate) in $20 \mathrm{mM} \mathrm{NaOH}$ and they were labelled as ErGO_AgNP. Similarly, MX_AgNP powders were dispersed in DW $\left(1 \mathrm{mg} \mathrm{mL}^{-1}\right)$ and dispersed in the ultrasonic bath for $30 \mathrm{~min} .10 \mu \mathrm{L}$ of the prepared dispersion was applied on GCE surface and let to dry out under nitrogen stream. These electrodes were labelled as GCE $\mid$ MX_AgNP. If necessary, incubation time was indicated in the text using labels GCE|MX_AgNP10, GCE|MX_AgNP2 and GCE|MX_AgNP24 to distinguish electrodes modified by dispersions prepared by $10 \mathrm{~min}, 2 \mathrm{~h}$ and $24 \mathrm{~h}$ incubation, respectively.

\section{Material characterization}

X-ray diffraction (XRD) spectra were collected using Philips X'PertPRO (Malvern PANanalytical, Netherland) device with $\mathrm{Cu} \mathrm{K} 1 \alpha$ primary $\mathrm{X}$-ray source with wavelength $0.15406 \mathrm{~nm}$, in a "Gonio" mode, angle range $5-60^{\circ}$, step size $0.0263^{\circ}$. The measured samples were MX_AgNP dispersions casted on a glass slide in the same manner as on the GCE surfaces.

UV-VIS measurements were performed with diluted aqueous dispersions (concentration not determined) of the prepared nanoparticles using UNICAM UV500 (Thermo-Fisher, USA), X-ray fluorescence (XRF) spectra were obtained from powder samples directly loaded into sample chamber of ElvaX device (Elvatech, Ukraine).

Atomic absorption spectrometry (AAS) was applied to solutions obtained after overnight leaching of MX_AgNP or GO_AgNP dispersions with $25 \mathrm{~mL}$ of $5 \% \mathrm{HNO}_{3}$ and the consequent filtration. Calibration solutions for these determinations were prepared by mixing known amount of pristine MXene dispersion with the respective amount of $\mathrm{AgNO}_{3}$ to achieve different silver concentrations, volume of the mixture was then adjusted to $25 \mathrm{~mL}$ by $5 \% \mathrm{HNO}_{3}$. Consequent incubation and filtration steps were identical to the one took with MX_AgNP samples. AAS spectra were measured using ContrAA 800 D device (Analytik Jena AG, Germany).

Samples for atomic force microscopy (AFM) was prepared by dropping diluted dispersions of the investigated samples on glass slides, drying it out under normal pressure, room temperature. Such modified glasses were fixed in the sample holder of the NTEGRAPRIMA atomic force microscope (NT-MDT Spectrum Instruments, Russia) equipped with silicon nitride probe $\mathrm{NSG}_{01}$ with a typical resonant frequency about $150 \mathrm{kHz}$ and a spring constant of $5.1 \mathrm{~N} \mathrm{~m}^{-1}$ (NT-MDT). Scanning was performed under room temperature, normal atmospheric pressure, in semicontact mode. Gwyddion 2.55 software was used for data evaluation. Samples for X-ray photoelectron spectroscopy (XPS) were prepared in the same way, only with more concentrated dispersions. XPS signals were recorded using a Thermo Scientific K-Alpha compact XPS system (Thermo Fisher Scientific, UK) equipped with a micro-focused, monochromatic Al K $\alpha$ X-ray source $(1486.68 \mathrm{eV})$. The spectra were acquired in the constant analyzer energy mode with the pass energy of $200 \mathrm{eV}$ for the survey. Narrow regions were collected with the pass energy of $50 \mathrm{eV}$. Charge compensation was achieved with the system Ar flood gun. Thermo Scientific Avantage software, version 5.9921 (Thermo Fisher Scientific), was used for digital acquisition and data processing. Spectral calibration was determined using the automated calibration routine and the internal $\mathrm{Au}, \mathrm{Ag}$ and $\mathrm{Cu}$ standards supplied with the K-Alpha system. The surface compositions (in atomic \%) were determined 
by considering the integrated peak areas of detected atoms and the respective sensitivity factor. To achieve scanning electron microscopy (SEM) images, sample dispersions were drop-casted on SEM sample grid, dried under the normal air at room temperature. The data were acquired by Nova NanoSEM 450 (FEI, USA).

HPLC measurements were performed with model 1260, Agilent Infinity Prime LC (Agilent, United States) equipped with a column RRHD extend C-18, 3.0x100 mm, $1.8 \mu \mathrm{m}$, 1200 bar (Agilent, United States)

\section{Electrochemical measurements and real samples preparation}

All measurements were performed in glass electrochemical cell under room temperature using platinum foil auxiliary electrode (Metrohm, Switzerland), $\mathrm{Ag} / \mathrm{AgCl} / 3 \mathrm{M} \mathrm{KCl}$ reference electrode (Metrohm, Switzerland), and modified glassy carbon (GCE) electrodes as the working ones. The electrodes were connected to potentiostat/galvanostat Autolab PGSTAT204 (Metrohm, Switzerland) connected to PC equipped with controlling software NOVA 2.1. Other measurement parameters (i.e. electrolyte composition, potential range and other details of measurement methods) are provided at respective places in the text.

To investigate the behavior of the sensors in real environment, soil samples were taken from public park (city of Zlin, Czech republic) and from forest near the same location. They were dried at free atmosphere, room temperature, sieved through 10 mesh sieve and mixed with metazachlor. Such samples were, alongside with the blank soil samples without metazachlor as the negative control, mixed with $100 \mathrm{~mL}$ of $20 \mathrm{mM} \mathrm{NaOH}$ and shaken for 24 hours with a speed of $120 \mathrm{~min}^{-1}$. After this step, mixtures were centrifuged (20 min, 10000 RPM), precipitates were discarded and the supernatants were, after 1:1 dilution with $20 \mathrm{mM}$ $\mathrm{NaOH}$, assessed by electrochemical method mentioned further in the text. These samples are labeled as "real". The theoretical concentrations of metazachlor in leachate from park soil (samples labeled as P) was $83 \mathrm{mg} \mathrm{L}^{-1}$ and in forest soil leachate (labeled as F) it was $71.4 \mathrm{mg}$ $\mathrm{L}^{-1}$. Furthermore, portions of blank leachates were additionally mixed with metazachlor (samples labeled as "added") to reveal the influence of soil matrix during the leaching step. The theoretical concentrations of MZCh "added" samples were $50 \mathrm{mg} \mathrm{L}^{-1}$ for both forest and park soil leachates.

\section{Results and Discussion}

\section{Characterization of $M X_{-} A g N P$}

In the first step elementary composition of the prepared MX_AgNP was examined using XRF. The spectra of all samples revealed significant fluorescence peak at $4.5 \mathrm{keV}$ which has been attributed to Ti. Furthermore, peaks at 22.1 and $24.9 \mathrm{keV}$ appeared in XRF spectra of all MX_AgNP samples assigned to $\mathrm{K} \alpha$ and $\mathrm{K} \beta$ lines of Ag (figure S1). The spectra were processed by the Elvatech software to obtain the percentage content of the selected elements, i.e. Ti, Ag and Mo (the last one appeared in all spectra probably as an impurity). The results have revealed 1.80, 4.72 and $8.35 \%$ of Ag in MX_AgNP samples prepared by $10 \mathrm{~min}, 2 \mathrm{~h}$ and $24 \mathrm{~h}$ incubation, respectively. These values cannot be treated as a bulk amount of silver in the prepared samples because i) XRF is a surface-analysis method and ii) measurements do not include light elements (i.e. C). They have only confirmed the fact that the silver amount 
increased with the increased incubation time. AAS of the acidic leachate from the MX_AgNP samples has confirmed absence of $\mathrm{Ag}$ in pristine MXene sample and its presence in all MX_AgNP samples with increasing concentration from 1.25 (MX_AgNP10) and $3.40 \%$ (MX_AgNP2) up to $11.93 \%$ w/w (MX_AgNP24). While the ratio between Ag content of MX_AgNP10 and MX_AgNP2 is quite similar for XRF (2.6) and AAS (2.7), $24 \mathrm{~h}$ incubation obviously led to substantially higher Ag content determined by bulk AAS method (9.5-fold higher Ag content compared to MX_AgNP10) than by the surface XRF (4.6-fold higher Ag content compared to MX_AgNP10). This fact may suggest thatthe prolonged incubation leads to the integration of silver also into the inner structure of MXene particles/agglomerates. It should be noted that the same method revealed only about $0.2 \%(\mathrm{w} / \mathrm{w})$ of silver in $\mathrm{GO}$ AgNP material ${ }^{54}$.

Information on redox state of Ti and Ag in MX_AgNP samples were acquired by XPS. Figure S1C-E shows XPS doublet peaks in Ag3d with the Ag3d5/2 components centered around $367.6 \mathrm{eV}$, except for the MX_AgNP2 where the peak emerged at $373.98 \mathrm{eV}$ and $\mathrm{Ag} 3 \mathrm{~d} 3 / 2$ component separated by $6 \mathrm{eV}$. According to the literature this can be attributed to silver in prevalently reduced form ${ }^{50,60,61}$. GO_AgNP exhibited the same XPS features, but FWHM parameter of the main peak was higher than 0.9 (about 1.12) which is typical for more oxidized form of silver ${ }^{61}$. Ti2 $p$ region scanning for MX_AgNP samples revealed peaks at 458.19, 458.28 and $458.43 \mathrm{eV}$ for MX_AgNP10, MX_AgNP2 and MX_AgNP24, respectively. In addition to this, also peaks at about $464.5 \mathrm{eV}$ were observed for all samples which can be attributed to highly oxidized $\mathrm{Ti}$ in $\mathrm{TiO}_{2}$. It should be also noted that small peak at about $453 \mathrm{eV}$ which can be attributed to Ti with low or zero valency was observed at MX_AgNP10 sample. All these results confirm the theory that the reduction of silver ions is accompanied by the complimentary oxidation of Ti atoms in MXene. It can be also seen from XPS spectra in figure S1 C-H that even after $10 \mathrm{~s}$ bombardment of the samples by Ar ions in order to reach belowthe-surface layers for analysis, the measured peak patterns have not changed significantly. It can be concluded that redox states of $\mathrm{Ag}$ and $\mathrm{Ti}$ are stable and invulnerable to further redox transformations.

UV-vis spectroscopy revealed the absorption peak at about $290 \mathrm{~nm}$ (figure 1A) which could be ascribed to oxidized moieties in MXene after incubation with oxidizing $\mathrm{Ag}^{+}$ions ${ }^{60,62}$, 63. This was supported also by a fact that the intensity of this absorption band is lowest for the untreated MXene sample while with increasing incubation time the absorbance band increases. Furthermore, broad adsorption band at about $400 \mathrm{~nm}$ wavelength was observed at sample MX_AgNP2h which may be correlated to a presence of silver nanoparticles providing surface plasmon signals. The broadness of the band most probably indicated quite broad size distribution of the synthesized Ag nanoparticles. The main results from UV-vis characterization of GO_AgNP samples (data not shown) were that i) GO retained its oxidized form even after the reduction of $\mathrm{Ag}^{+}$and ii) that the absorption pattern typical for silver nanoparticles was not observed, most probably due to a lower $\mathrm{pH}$ and the small size of the synthesized nanoparticles. This is in accordance with other authors who observed that the typical surface plasmon signal is conditioned by alkali solution ${ }^{64,65}$ while Evanoff and Chumanov ${ }^{66}$ reported on correlation between low size of nanoparticles and their decreased absorbance.

To achieve more information about (Er)GO_AgNP, FTIR analysis was performed on ErGO and ErGO_AgNP film peeled off from GCE electrodes. The obtained data were 
normalized according to the peak at $1630 \mathrm{~cm}^{-1}$ ascribed to vibration of conjugated bonds in non-oxidized graphene allowing for semiquantitative evaluation of the obtained spectra. It was observed (see figure S2) that both reduced samples exhibited a broad absorption band at about $3400 \mathrm{~cm}^{-1}$ attributed to hydroxyls from adsorbed water molecules. This band was, however, much lower than bands in the samples measured before the reduction which can be explained in terms of decreased hydrophilicity - a phenomenon typical for the reduced GO ${ }^{67}$. Another interesting result is the emergence of absorption bands at about $1080 \mathrm{~cm}^{-1}(\mathrm{C}-\mathrm{O}$ in alkoxy group ${ }^{68-70}$ ) observed in GO_AgNP and ErGO_AgNP samples with much higher intensity than in GO and ErGO sample (in the latter one, this band diminished entirely). It may sound in the contradiction with previous findings ${ }^{54}$ where incubation of $\mathrm{GO}$ with $\mathrm{Ag}^{+}$was accompanied by decrease of $1080 \mathrm{~cm}^{-1}$ band. However, it should be noted that the samples here were measured on films pealed-off from the carbon electrode surfaces, not only deposited on aluminium foil. Such arrangement and interactions of GO( $\mathrm{AgNP})$ sheets may be responsible for observed increase of alkoxy/epoxy moieties. However equivocal are these results, there is the unambiguous and more intriguing fact that the discussed epoxy groups have been retained after the electrochemical reduction, together with the edge and "bulk" -OH moieties represented by bands 1450 and $1375 \mathrm{~cm}^{-1}$, respectively ${ }^{71}$. Without silver, all the discussed groups have almost entirely diminished after the reduction, or, at least, drop significantly. It may indicate that $\mathrm{Ag}^{+}$ions attached to $\mathrm{GO}$ serve as protection to $\mathrm{C}-\mathrm{O}$ moieties. More probable explanation of this observation is that the oxidized silver atoms indicated by XPS served as the electron acceptors during the reduction process, rather than oxygen moieties. As a result, the partially oxidized structure of the original $\mathrm{GO}$ is, at certain rate, protected by the adsorbed Ag, which may play very significant role in antifouling or repulsion of potentially interfering compounds (see the section "Electrochemical detection of metazachlor").

XRD spectroscopy revealed that all MXene-basded samples, excluding pristine MXene, exhibited diffraction peaks at Bragg's angle of about $38^{\circ}$ (see figure 1B) attributed to (111) plane of face-centered cubic Ag crystalline phase ${ }^{60,62}$. From Bragg's formula, the lattice constant was calculated to be $0.24 \mathrm{~nm}$ for all samples, from which it can be concluded that the chemistry of AgNP synthesis is the same regardless of the incubation time. Similar results have been reported, for example, by Zou et al. who observed zero change in "Ag peak" position at MXene/AgNPs prepared with different precursor concentrations ${ }^{59}$. From XRD peaks an approximate crystallite sizes were also calculating using Scherrer's formula. Sizes of 32.7, 30.8 and $23.8 \mathrm{~nm}$ were obtained for MX_AgNP10, MX_AgNP2 and MX_AgNP24, respectively, suggesting that the longer time of incubation lead to a certain decrease in particle size. The calculated size also corresponds well with those reported by Zou et al. ${ }^{59}$. Interestingly, the typical XRD peaks were not detected in any GO_AgNP sample (data not shown), most probably as a result of their small size ${ }^{54}$.

\section{Here figure 1}

AFM analysis (see figure S3) revealed that the pristine $\mathrm{Ti}_{3} \mathrm{C}_{2} \mathrm{~T}_{\mathrm{X}}$ MXene was partly exfoliated down to single-layer particles up to stacked multi-layered particles. Lateral size of the former was from several $\mathrm{nm}$ up to $\mu \mathrm{m}$ range and their thickness was about $2 \mathrm{~nm}$, what is in agreement with other observations ${ }^{72}$. The latter type of particles tended to stack into even 
larger ( $\mu \mathrm{m}$ range in all aspects) aggregates with the observable layered patterns typical for MXenes. MX_AgNP2 samples exhibited similar behavior, but with some small and regular features which may be attributed to silver nanoparticles. These objects exhibited significantly different probe phase shift detected during the AFM scanning alongside the sample topography what strongly supports the presumption that their composition differs from the rest of the scanned material. The height of those features was estimated by evaluation of curves obtained by topography profiling of AFM scans and a value of $10.8 \pm 0.7 \mathrm{~nm}$ was observed. These features were observed also on MX_AgNP24 sample, but their size was smaller, only $5.4 \pm 1.4$ $\mathrm{nm}$. It is important to note that the discussed sizes implied only to the smallest observed objects, but besides them, also a number of bigger or clustered particles was observed. Their size distribution was obviously broader for MX_AgNP2 than for MX_AgNP24 sample. On the other side, these large Ag clusters were generally not observed in the GO_AgNP sample, where only small nanoparticles decorating the GO sheets were found (see figure S4)

The selected nanohybrids (MX_AgNP2 and GO_AgNP) were also investigated by SEM (figure 2), which confirmed the above-discussed AFM results. Specifically, large features were observed on surface of MX_AgNP2, irregular in shape and with apparently broad size distribution, while they were only scarcely seen on GO_AgNP. Under the given conditions, the smallest AgNPs could not be detected by the SEM. The SEM device was equipped by EDX (Energy dispersive X-Ray) module for determination of elementary composition of the measured samples. This technique revealed that both GO_AgNP and MX_AgNP2 exhibited the EDX signal typical for silver what confirmed the presence of silver nanoparticles on GO_AgNP and MX_AgNP2 surfaces (figure 2).

\section{Here figure 2}

\section{Electrochemical characterization}

\section{Electrochemistry without metazachlor}

Voltammetric measurements were performed with GCE electrodes covered with the synthesized nanomaterial MX_AgNP. Cyclic voltammetry (CV) scans in a higher potential range (see figure 3) revealed a pair of redox peaks attributed to oxidation and reduction ${ }^{73}$ of silver and the formed silver oxide, respectively ${ }^{30}$. Without the AgNP, MXene samples exhibited only an anodic wave attributed to oxidation of MXene's Ti to titanium oxide ${ }^{39}$. This oxidation occurred at about $150 \mathrm{mV} v s . \mathrm{Ag} / \mathrm{AgCl}$ reference electrode, which seems to disagree with data in a literature placing this peak to $430 \mathrm{mV}^{39,46}$, but owing to difference in the used electrolyte $\mathrm{pH}$ ( $\mathrm{pH} 7$ in the cited studies $v s . \mathrm{pH}$ above 12 in our measurements), such shift would be expected. The above-mentioned Ti oxidation was not observed at MX_AgNP samples most probably because $\mathrm{Ti}$ atoms have been already oxidized during reduction of $\mathrm{Ag}^{+}$ions. Contrary to GCE|MX_AgNPs, electrodes modified by ErGO_AgNP nanomaterial revealed very low electrochemical response of the adsorbed silver (figure $3 \mathbf{B}$ ), most probably because of the approximately 10-fold lower concentration of Ag in the ErGO_AgNP nanomaterial.

\section{Here figure 3}




\section{Response to metazachlor}

Voltammetric response to metazachlor $(1.12 \mathrm{mM}$ in $20 \mathrm{mM} \mathrm{NaOH})$ of the electrodes modified by the prepared nanomaterials was investigated using CV. First, higher potential range ( -0.2 to $+0.6 \mathrm{~V} v s$. $\mathrm{Ag} / \mathrm{AgCl}$ reference electrode) was chosen to examine a possibility of MZCh to be oxidized ${ }^{13,24}$. Results in figure 4 where the illustrative cyclic voltammograms of GCE electrodes modified with MX_AgNP24, MX, ErGO_AgNP and ErGO are shown suggested the probability of some response to metazachlor at GCE|MX_AgNP. It is observed as an emerged CV peak at about $0.45 \mathrm{~V}$. Further CV scanning, however, revealed that, after 3 successive CV scans, the peak has completely disappeared which makes this type of measurement unsuitable for MZCh sensing. CVs of GCE electrodes modified by MXene without silver nanoparticle have revealed also some oxidation process at about $0.5 \mathrm{~V}$, which was retained after repeated scanning. Nevertheless, the response is quite small what is not suitable for high-performance MZCh sensing too. The oxidation pattern and the oxidation currents achieved with GCE|MX were similar to the one observed at GCE electrodes coated with ErGO, (figure 4 D). The current response was not observed on GCEs modified by ErGO_AgNP nanomaterial (figure $4 \mathbf{C}$ ) and thus the oxidative potential range was recognized as inappropriate for the electrochemical MZCh detection.

In the next series of experiments $\mathrm{CVs}$ were performed in reducing potential window (1.5 to $0 \mathrm{~V} v s . \mathrm{Ag} / \mathrm{AgCl}$ reference electrode). From background-corrected cathodic parts of $\mathrm{CVs}$ an emergence of cathodic current wave in the presence of metazachlor $(1.15 \mathrm{mM})$ can be seen for both GCE $\mid \mathrm{MX} \_\mathrm{AgNP}$ and GCE $\mid \mathrm{ErGO} \_\mathrm{AgNP}$ (figure $5 \mathbf{A}$ and $\mathbf{B}$, respectively) and presumably points to the dechlorination process, as suggested from results published elsewhere 15, 20,26, 29, 30. To confirm that, measurements were performed with the MZCh metabolite (MZCh OA) where the chlorine moiety is replaced, therefore dechlorination cannot occur. Absence of the clear reduction current in this case, as illustrated in the figure S5, is the experimental support for the claim that the observed reduction wave results from dechlorination process. Equally important result here is that the observed reduction current is much higher when $\mathrm{Ag}$ nanoparticles are integrated with ErGO and MXene compared to response obtained with pristine nanomaterials. MX_AgNP exhibited also a significant shift of reduction current onset (from approx. -1040 to $-600 \mathrm{mV}$ vs. $\mathrm{Ag} / \mathrm{AgCl}$ reference electrode in case of MX and MX_Ag, respectively).

The above-mentioned results clearly indicated the positive influence of the silver moieties to electrocatalysis of reductive dechlorination of $\mathrm{MZCh}$ as well as the suitability of negative potential window for further measurements.

\section{Here figure 4 \\ Here figure 5}

It has been reported that electrochemical dechlorination of chloroacetanilide pesticide is efficient in alkali environment ${ }^{26,28}$, as well as in $\mathrm{Na}_{2} \mathrm{SO}_{4}\left(\right.$ ref $\left.^{16}\right)$. Therefore, the influence of the electrolyte composition $\left(20,100,500 \mathrm{mM} \mathrm{NaOH}\right.$ and $100 \mathrm{mM} \mathrm{Na}_{2} \mathrm{SO}_{4}$ ) was investigated. In figure S6 voltammograms obtained in presence of $0.75 \mathrm{mM} \mathrm{MZCh}$ dissolved in different solutions are shown. From these results it is clear that the highest reduction currents were achieved in a low concentration $(20 \mathrm{mM}) \mathrm{NaOH}$ (approx. 6.3 and $6.1 \mu \mathrm{A}$ at -1290 and -850 
$\mathrm{mV}$ for MX- and ErGO- based nanomaterials, respectively) while higher concentrations (i.e. 100 and $500 \mathrm{mM} \mathrm{NaOH}$ ) slightly decreased the measured voltammetric response. For both MX_AgNP and ErGO_AgNP the response obtained in $500 \mathrm{mM} \mathrm{NaOH}$ was close to the response obtained in $20 \mathrm{mM} \mathrm{NaOH}$ while the lowest responses were observed in $100 \mathrm{mM}$ $\mathrm{NaOH}$. In summary, the results confirmed that $20 \mathrm{mM} \mathrm{NaOH}$ is enough concentration for efficient electroreductive dechlorination. In case of a neutral solution $\mathrm{Na}_{2} \mathrm{SO}_{4}$ no voltammetric response was observed when unmodified GCE and the GCE modified by MX_AgNP were used. Approximately $3 \mu \mathrm{A}$ response was recorded for GCE modified by ErGO_AgNP what is significantly lower than the maximum response obtained in $20 \mathrm{mM} \mathrm{NaOH}$. The results indicates the unsuitability of $\mathrm{Na}_{2} \mathrm{SO}_{4}$ as the supporting electrolyte, but also indicated the ErGO_AgNP is more efficient electrocatalyst even in non-optimal conditions, compared to MX_AgNP. It has been proposed that efficiency of reductive dechlorination is conditioned by formation of adsorbed hydrogen $\left(\mathrm{H}_{\mathrm{ads}}\right)$ and determined by the rate at which these species are consumed by either hydrogen evolution reaction (HER) or dechlorinatin ${ }^{74}$. $\mathrm{pH}$ was found to play a role in this equilibrium in a way that acidic environment promote HER, mainly by supplying $\mathrm{H}^{+}$ions for forming $\mathrm{H}_{\text {ads }}\left({ }^{74}\right.$ and references therein) which could explain higher response at alkali conditions over the neutral solution. Apart from the $\mathrm{pH}$ value, effect of electrolyte concentration should be accounted since it was shown that it can also shift potential of the dechlorination reaction ${ }^{74}$. In the case of MX_AgNP, similar effect could be observed, i.e. shift of the onset of the reaction to approximately $-1000 \mathrm{mV}$ at $500 \mathrm{mM} \mathrm{NaOH}$, compared to $-600 \mathrm{mV}$ recorded at 10 -fold lower concentration of the electrolyte (see figure S6). This shift was not observed at $100 \mathrm{mM} \mathrm{NaOH}$, where the above-mentioned "lack of $\mathrm{H}^{+ \text {" }}$ effect may play role.

Another parameter was the incubation time during a synthesis of MX_AgNP. Its influence was investigated employing $\mathrm{CV}$ obtained at $20 \mathrm{mM} \mathrm{NaOH}$ containing $0.38 \mathrm{mM}$ MZCh. Results can be found in figure S7. It is not a surprise that MX_AgNP incubated for 10 minutes provided lowest response (average response of $-2.8 \mu \mathrm{A}$ at $-1.35 \mathrm{~V}$ ) while 2 hours incubation increased the maximum response to $-4.45 \mu \mathrm{A}$ achieved at $-1.15 \mathrm{~V}$. MX_AgNP24 returned a higher response $(-5.99 \mu \mathrm{A}$ at $-1.1 \mathrm{~V})$ suggesting that the increase of a total $\mathrm{Ag}$ amount discussed in the "Characterization" section had some, but not significant effect on the electrocatalytic response gain. Therefore, 2-hour incubation was considered sufficient due to the significant time savings during preparation outweighing the response increase.

The reproducibility of the preparation protocol was tested by comparison of current responses read from background-corrected CVs at -1.18 V of ErGO_AgNP- and MX_AgNPmodified electrodes, in presence of $1.15 \mathrm{mM}$ MZCh. GCE $\mid \mathrm{MX} \_$AgNP and GCE|ErGO_AgNP electrodes exhibited relative standard deviations of $4.58 \%$ and $7.22 \%$, respectively (for $n=3$ ). Although the sensors prepared using MX_AgNP nanomaterial provided less scattered data, their analytical signal was lower (see the next section).

\section{Electrochemical detection of metazachlor}

In the next step, CV measurements in different concentrations of MZCh (figure 6) were performed to create the calibration curves. The measurements were evaluated as follows: background CVs obtained in blank solution $(20 \mathrm{mM} \mathrm{NaOH})$ were subtracted from the cathodic parts of CVs acquired in MZCh solutions, and the current value at $-1.18 \mathrm{~V}$ (maximum response) 
was the analytical signal. All measurements were made at least triplicate. Obtained calibration curve (figure 6) was linear only up to MZCh concentration of $104 \mathrm{mg} \mathrm{L}^{-1}(375 \mu \mathrm{M})$. In this region the calibration equation was $I[\mu \mathrm{A}]=0.0504( \pm 0.0037) \times c_{\mathrm{MZCh}}\left[\mathrm{mg} \mathrm{L}^{-1}\right]+0.4( \pm 0.2)$. From these values limit of detection (LOD) of $11.2 \mathrm{mg} \mathrm{L}^{-1}(40 \mu \mathrm{M})$ can be calculated when 3 times standard deviation of interpolated values for zero concentration is divided by the calibration line slope. The whole calibration curve can be also fitted using cubic function $I[\mu \mathrm{A}]$ $=0.23( \pm 0.14)+0.065( \pm 0.006) \times c_{\mathrm{MZCh}}-0.00014( \pm 0.00005) \times c_{\mathrm{MZCh}^{2}}+1.31( \pm 1.10) \times 10^{-7} \mathrm{x}$ $c_{\mathrm{MZCh}}{ }^{3}$. From obtained R-square values $(0.979$ and 0.998 for linear and cubic fitting, respectively) it can be seen that the cubing fitting is more precise. The calibration curve obtained with GCE $\mid$ ErGO_AgNP electrode provided linearity in the whole tested range of MZCh concentrations $(37-1123 \mu \mathrm{M})$ and a calibration equation of $I[\mu \mathrm{A}]=0.075( \pm 0.001) \mathrm{x}$ $c_{\mathrm{MZCh}}\left[\mathrm{mg} \mathrm{L}^{-1}\right]-0.24( \pm 0.18)$ with correlation coefficient of $\mathrm{R}^{2}=0.998$ and a detection limit of $7.43 \mathrm{mg} \mathrm{L}^{-1}(27 \mu \mathrm{mol})$. Obviously, ErGO_AgNP modification of electrodes enhanced the redox processes that are behind the electrochemical detection of MZCh. This fact can be attributed probably to higher electron conductivity of ErGO_AgNP compared to MX_AgNP as well as to the lower size of AgNP deposited on GO during the synthesis.

The achieved results cannot be directly compared with other metazachlor electrochemical sensors simply because none has been reported so far. In our previous work ${ }^{54}$ only the response of ErGO_AgNP electrode was observed in presence of metazachlor, but without further investigation of sensing performance. On the other hand, the herein described devices can be seen as higher-concentration sensors, compared to the only electrochemical sensor towards chloracetanilide herbicide based on its reductive electrodechlorination described to day (DC polarography, linear response between 0.1 and $10 \mu \mathrm{mol}$ of alachlor ${ }^{22}$ ). Although some other electrochemical methods for acetanilide detection have been reported, for example impedance molecular-imprinted polymer sensor detecting trace concentrations of alachlor ${ }^{75}$, their comparison in terms of performance may be somehow misleading since they do not share the functional fundamentals. It is also obvious that the achieved limits of detection cannot compete with conventional (liquid chromatography) methods, but they represent the important step towards more sensitive sensors since the operational properties can be further improved by, for example, changing the detection system from a batch into a flow-through one or by further optimizations. In addition, the proposed sensor could be employed in applications where a continuous detection of higher concentrations is required, like monitoring of pesticide releasing from particles or pesticide degradations ${ }^{17,30,76}$.

\section{Here figure 6}

To investigate operational features of the sensors in real sample matrix, cyclic voltammograms were performed with both GCE|MX_AgNP and GCE|MX_AgNP in 1:1 diluted leachate from park and forest soils (see the section Electrochemical measurements and sample preparation). Data were evaluated in the same way as for the calibration measurements described above. The results, expressed as the percentage of the expected theoretical concentrations, are summarized in the table 1. The values of only $17.4 \pm 5.5$ and $30.2 \pm 7.1 \%$ of expected responses for the "added" sample (MZCh added after the leaching step) suggest that MX_AgNP is much more prone to a signal interference caused by soil leachate content (mainly humic and fulvic acids 
${ }^{77}$ ). Differences in response corresponded also with the appearance of leachates - the forest soil leachate had less intensive color what indicates lower content of the dissolved organic matter compared to the park soil. The value of the response itself indicated that the GCE|MX_AgNP sensor is incapable to detect all metazachlor present in the solution. The electrode modified with ErGO_AgNP provided the precise information about the concentration of metazachlor added into leachates as indicated by $108 \pm 14$ and $110 \pm 7 \%$ response achieved. It can be claimed that this type of sensor is much more convenient for real sample measurements.

Interestingly, the $24 \mathrm{~h}$ incubation of soil+metazachlor in $20 \mathrm{mM} \mathrm{NaOH}$ (samples "real") significantly increased the voltammetric response, approximately 2.5 -fold, compared to the expected value, in case of ErGO_AgNP-modified electrodes. MX_AgNP sensors exhibited approximately two-fold increase of the percentage of the expected value (from $30.2 \pm 7.1$ to $60.9 \pm 11.3 \%$ ) in the park soil. However, the increase was much lower (from $17.4 \pm 5.5$ to $23.4 \pm 8.8 \%$ ) in the "poorer" forest soil. There are two possible explanations for such increased voltametric response. During the $24 \mathrm{~h}$ incubation, metazachlor underwent some reaction which enhanced the accessibility of chlorine atom to the electroactive sites of electrodes. It is known, for example, that metazachlor can be coagulated by interaction with humic acids ${ }^{78}$. Another explanation would be that the metazachlor concentration in the calibration solutions was lower than expected, probably because of low solubility. To assess this possibility, MTZCh concentration in the calibration solution was checked using HPLC. It was found that the estimated concentration of the metazachlor $\left(0.51 \mu \mathrm{g} \mathrm{L} \mathrm{L}^{-1}\right.$, prepared from the MZCh stock solution in $20 \mathrm{mM} \mathrm{NaOH}$ - the same that was used for the sensors calibration) was very close to the obtained value $\left(0.5 \pm 0.01 \mu \mathrm{g} \mathrm{L}^{-1}\right)$. These results confirmed no systemic error in the calibration measurements. In the real samples, humic acid might increase metazachlor solubility ${ }^{79}$ and thus also the voltammetric response. Such effect was observed only after $24 \mathrm{~h}$ incubation, not after the immediate mixing of metazachlor solution with the leachates, and should be addressed in some more extended study, beyond the scope of this work.

Here table 1

\section{Conclusions}

In this work the electrochemical behavior of metazachlor, a frequently used chloroacetanilide herbicide, was investigated in order to establish a way for its electrochemical detection. To achieve this, silver nanoparticles synthesized on graphene oxide (GO_AgNP with consequent reduction to electrochemically reduced ErGO_AgNP) and $\mathrm{Ti}_{3} \mathrm{C}_{2} \mathrm{~T}_{\mathrm{X}}$ MXene (MX_AgNP) were prepared simply by stirring of GO or MXene with solution of $\mathrm{AgNO}_{3}$. It was found that electrodes modified by these nanomaterials could record some reduction process in alkali solution containing metazachlor while no significant oxidation processes have been observed under the same conditions. The observed reduction started at about $-600 \mathrm{mV}$ vs. $\mathrm{Ag} / \mathrm{AgCl} / 3 \mathrm{M} \mathrm{KCl}$ reference electrode and the faradaic currents related to this process were significantly higher in presence of silver nanoparticles in comparison with bare ErGO and MXene. The presence of silver nanoparticles caused a significant shift (by approximately 400 $\mathrm{mV}$ towards less negative potential) of the potential where metazachlor reduction starts which points to enhanced electrocatalytic activity of silver nanoparticles towards the observed process. Assumption has been made that metazachlor undergoes electrochemical reductive 
dechlorination - a process that has been described before and which is catalysed by silver, either in "macro-" or nano- form.

The performed experiments also led to a conclusion that ErGO_AgNP is more efficient in terms of electrocatalysis of the metazachlor dechlorination which is displayed as larger faradaic currents, even though the total amount of silver in ErGO_AgNP was found to be approximately ten-fold lower. The conclusion was that the size of AgNP is a key factor here very small (units of $\mathrm{nm}$ ) AgNPs synthesized on GO performed obviously much better than approximately $10 \mathrm{~nm}$ (and larger) nanoparticles formed on MX_AgNP.

In accordance with previous experiments, the electrochemical MZCh sensor employing ErGO_AgNP performed much better than its MX_AgNP counterpart. While the former exhibited linear range $37-1123 \mu \mathrm{M}$ and detection limit of $27 \mu \mathrm{M}$, the latter exhibited linear correlation and detection limit only $37-375 \mu \mathrm{M}$ and $40 \mu \mathrm{M}$, respectively. Determination of metazachlor was performed in alkali leachates of park and forest soil, as well. It was found that ErGO_AgNP modification is more convenient because it exhibited resiliency towards interferences caused by humic acids. But the long-term incubation of metazachlor with soil leachates led to an unexpected increase of the voltammetric response for both electrodes.

\section{Acknowledgments}

This study was supported by Grant Agency of Czech Republic by a project with a contract number GACR 20-27735Y. The authors acknowledge very kind help of Dr. Antonin Minarik (Polymer center of Faculty of Technology, Tomas Bata University) with AFM measurements. Authors also acknowledge XRD measurements performed by prof. Roman Cermak, $\mathrm{PhD}$ (Faculty of Technology, Tomas Bata University) and Dr. Matej Micusik (Polymer Institute, Slovak Academy of Sciences) for XPS analyses. 


\section{References:}

1. Liang, H. C.; Bilon, N.; Hay, M. T., Analytical Methods for Pesticide Residues in the Water Environment. Water Environment Research 2015, 87 (10), 1923-1937.

2. Garrido, E. M.; Delerue - Matos, C.; Lima, J. L. F. C.; Brett, A. M. O., Electrochemical Methods in Pesticides Control. Analytical Letters 2004, 37 (9), 1755-1791.

3. Gajdar, J.; Horakova, E.; Barek, J.; Fischer, J.; Vyskocil, V., Recent Applications of Mercury Electrodes for Monitoring of Pesticides: A Critical Review. Electroanalysis 2016, 28 (11), 2659-2671.

4. Fischer, J.; Barek, J.; Wang, J., New Methods for Electrochemical Determination of Pesticides (A Review). 2012; pp 79-86.

5. Barbosa, P. F. P.; Vieira, E. G.; Cumba, L. R.; Paim, L. L.; Nakamura, A. P. R.; Andrade, R. D. A.; do Carmo, D. R., Voltammetric techniques for pesticides and herbicides detection- an overview. International Journal of Electrochemical Science 2019, 14 (4), 3418-3433.

6. Gonçalves-Filho, D.; Silva, C. C. G.; De Souza, D., Pesticides determination in foods and natural waters using solid amalgam-based electrodes: Challenges and trends. Talanta 2020, 212, 120756.

7. Pundir, C. S.; Malik, A.; Preety, Bio-sensing of organophosphorus pesticides: A review. Biosensors and Bioelectronics 2019, 140, 111348.

8. Zhao, F.; Wu, J.; Ying, Y.; She, Y.; Wang, J.; Ping, J., Carbon nanomaterial-enabled pesticide biosensors: Design strategy, biosensing mechanism, and practical application. TrAC Trends in Analytical Chemistry 2018, 106, 62-83.

9. European Food Safety, A.; Brancato, A.; Brocca, D.; Bura, L.; Byers, H.; Chiusolo, A.; Court Marques, D.; $\quad$ Crivellente, F.; De Lentdecker, C.; De Maglie, M.; Egsmose, M.; Erdos, Z.; Fait, G.; Ferreira, L.; Goumenou, M.; Greco, L.; Istace, F.; Jarrah, S.; Kardassi, D.; Leuschner, R.; Lythgo, C.; Magrans, J. O.; Medina, P.; Miron, I.; Molnar, T.; Nougadere, A.; Padovani, L.; Parra Morte, J. M.; Pedersen, R.; Reich, H.; Sacchi, A.; Santos, M.; Serafimova, R.; Stanek, A.; Sturma, J.; Tarazona, J.; Terron, A.; Theobald, A.; Vagenende, B.; Verani, A.; Villamar-Bouza, L., Peer review of the pesticide risk assessment for the active substance metazachlor in light of confirmatory data submitted. EFSA Journal 2017, 15 (6), e04833.

10. Hvězdová, M.; Kosubová, P.; Košíková, M.; Scherr, K. E.; Šimek, Z.; Brodský, L.; Šudoma, M.; Škulcová, L.; Sáňka, M.; Svobodová, M.; Krkošková, L.; Vašíčková, J.; Neuwirthová, N.; Bielská, L.; Hofman, J., Currently and recently used pesticides in Central European arable soils. Science of The Total Environment 2018, 613-614, 361-370.

11. Weber, G.; Christmann, N.; Thiery, A.-C.; Martens, D.; Kubiniok, J., Pesticides in agricultural headwater streams in southwestern Germany and effects on macroinvertebrate populations. Science of The Total Environment 2018, 619-620, 638-648.

12. Velisek, J.; Stara, A.; Kubec, J.; Zuskova, E.; Buric, M.; Kouba, A., Effects of metazachlor and its major metabolite metazachlor OA on early life stages of marbled crayfish. Scientific Reports 2020, $10(1), 875$.

13. Wei, J.; Feng, Y.; Sun, X.; Liu, J.; Zhu, L., Effectiveness and pathways of electrochemical degradation of pretilachlor herbicides. Journal of Hazardous Materials 2011, 189 (1), 84-91. 
14. Sauro, V. A.; Magri, D. C.; Pitters, J. L.; Workentin, M. S., The electrochemical reduction of 1,4dichloroazoethanes: Reductive elimination of chloride to form aryl azines. Electrochimica Acta 2010, 55 (20), 5584-5591.

15. He, W. Y.; Fontmorin, J. M.; Hapiot, P.; Soutrel, I.; Floner, D.; Fourcade, F.; Amrane, A.; Geneste, F., A new bipyridyl cobalt complex for reductive dechlorination of pesticides. Electrochimica Acta 2016, 207, 313-320.

16. He, W.; Fontmorin, J.-M.; Soutrel, I.; Floner, D.; Fourcade, F.; Amrane, A.; Geneste, F., Reductive dechlorination of a chloroacetanilide herbicide in water by a Co complex-supported catalyst. Molecular Catalysis 2017, 432, 8-14.

17. Zhu, K.; Baig, S. A.; Xu, J.; Sheng, T.; Xu, X., Electrochemical reductive dechlorination of 2,4dichlorophenoxyacetic acid using a palladium/nickel foam electrode. Electrochimica Acta 2012, 69, 389-396.

18. Pasciak, E. M.; Sengupta, A.; Mubarak, M. S.; Raghavachari, K.; Peters, D. G., Electrochemical reduction of 2-chloro-N-phenylacetamides at carbon and silver cathodes in dimethylformamide. Electrochimica Acta 2014, 127, 159-166.

19. Pasciak, E. M.; Peters, D. G., Reduction of Substituted Phenyl 2-Chloroacetates at Silver Cathodes: Electrosynthesis of Coumarins. Journal of The Electrochemical Society 2014, 161 (12), G98-G102.

20. Verlato, E.; He, W.; Amrane, A.; Barison, S.; Floner, D.; Fourcade, F.; Geneste, F.; Musiani, M.; Seraglia, R., Preparation of Silver-Modified Nickel Foams by Galvanic Displacement and Their Use as Cathodes for the Reductive Dechlorination of Herbicides. ChemElectroChem 2016, 3 (12), 2084-2092.

21. Yin, H.; Cao, X.; Lei, C.; Chen, W.; Huang, B., Insights into Electroreductive Dehalogenation Mechanisms of Chlorinated Environmental Pollutants. ChemElectroChem 2020, 7 (8), 1825-1837.

22. Carrai, P.; Nucci, L.; Pergola, F., Polarographic Behaviour of Alachlor Application to Analytical Determination. Analytical Letters 1992, 25 (1), 163-172.

23. Ajermoun, N.; Aghris, S.; Farahi, A.; Lahrich, S.; Saqrane, S.; Bakasse, M.; El Mhammedi, M. A., Electrochemical reduction of neonicotinoids insecticides catalysed by metallic silver: case of the detection of imidacloprid in tomato and orange juices. International Journal of Environmental Analytical Chemistry 2019, 1-13.

24. Jevtić, S.; Vukojević, V.; Djurdjić, S.; Pergal, M. V.; Manojlović, D. D.; Petković, B. B.; Stanković, D. M., First electrochemistry of herbicide pethoxamid and its quantification using electroanalytical approach from mixed commercial product. Electrochimica Acta 2018, 277, 136-142. 25. Bandžuchová, L.; Švorc, L.; Sochr, J.; Svítková, J.; Chýlková, J., Voltammetric method for sensitive determination of herbicide picloram in environmental and biological samples using borondoped diamond film electrode. Electrochimica Acta 2013, 111, 242-249.

26. Lou, Y.-Y.; He, W.; Verlato, E.; Musiani, M.; Floner, D.; Fourcade, F.; Amrane, A.; Li, C.; Tian, Z.-Q.; Merdrignac-Conanec, O.; Coulon, N.; Geneste, F., Ni-coated graphite felt modified with $\mathrm{Ag}$ nanoparticles: A new electrode material for electro-reductive dechlorination. Journal of Electroanalytical Chemistry 2019, 849, 113357.

27. He, W.; Lou, Y.; Verlato, E.; Soutrel, I.; Floner, D.; Fourcade, F.; Amrane, A.; Musiani, M.; Geneste, F., Reductive dehalogenation of a chloroacetanilide herbicide in a flow electrochemical cell fitted with Ag-modified $\mathrm{Ni}$ foams. Journal of Chemical Technology \& Biotechnology 2018, 93 (6), 1572-1578. 
28. Lou, Y.-Y.; Geneste, F.; Soutrel, I.; Amrane, A.; Fourcade, F., Alachlor dechlorination prior to an electro-Fenton process: Influence on the biodegradability of the treated solution. Separation and Purification Technology 2020, 232, 115936.

29. Liu, B.; Hu, X.; Deng, Y.; Yang, S.; Sun, C., Electrocatalytic dechlorination of chloroacetic acids by silver nanoparticles modified glassy carbon electrode. Journal of Solid State Electrochemistry 2012, 16 (3), 927-930.

30. Liu, B.; Ding, C.; Xiao, B.; Cui, L.; Wang, M., Electrocatalytic dechlorination of chloroacetic acids on silver nanodendrites electrode. Materials Science and Engineering: C 2014, 37, 108-112.

31. Shevchenko, A. P.; Aksimentyeva, E. I.; Lut, E. A., Reduction of chloroacetic acid on nanostructured nickel electrodes. Russian Journal of Electrochemistry 2015, 51 (11), 1041-1045.

32. Ghidiu, M.; Lukatskaya, M. R.; Zhao, M.-Q.; Gogotsi, Y.; Barsoum, M. W., Conductive twodimensional titanium carbide 'clay' with high volumetric capacitance. Nature 2014, 516 (7529), 78-81. 33. Naguib, M.; Gogotsi, Y., Synthesis of Two-Dimensional Materials by Selective Extraction. Accounts of Chemical Research 2015, 48 (1), 128-135.

34. Naguib, M.; Kurtoglu, M.; Presser, V.; Lu, J.; Niu, J.; Heon, M.; Hultman, L.; Gogotsi, Y.; Barsoum, M. W., Two-Dimensional Nanocrystals Produced by Exfoliation of Ti3AIC2. Advanced Materials 2011, 23 (37), 4248-4253.

35. Chaudhari, N. K.; Jin, H.; Kim, B.; San Baek, D.; Joo, S. H.; Lee, K., MXene: an emerging two-dimensional material for future energy conversion and storage applications. Journal of Materials Chemistry A 2017, 5 (47), 24564-24579.

36. Jiang, C.; Wu, C.; Li, X.; Yao, Y.; Lan, L.; Zhao, F.; Ye, Z.; Ying, Y.; Ping, J., Allelectrospun flexible triboelectric nanogenerator based on metallic MXene nanosheets. Nano Energy 2019, 59, 268-276.

37. Soomro, R. A.; Jawaid, S.; Zhu, Q.; Abbas, Z.; Xu, B., A mini-review on MXenes as versatile substrate for advanced sensors. Chinese Chemical Letters 2020, 31 (4), 922-930.

38. Kalambate, P. K.; Gadhari, N. S.; Li, X.; Rao, Z.; Navale, S. T.; Shen, Y.; Patil, V. R.; Huang, Y., Recent advances in MXene-based electrochemical sensors and biosensors. TrAC Trends in Analytical Chemistry 2019, 120, 115643.

39. Lorencova, L.; Bertok, T.; Dosekova, E.; Holazova, A.; Paprckova, D.; Vikartovska, A.; Sasinkova, V.; Filip, J.; Kasak, P.; Jerigova, M.; Velic, D.; Mahmoud, K. A.; Tkac, J., Electrochemical performance of Ti3C2Tx MXene in aqueous media: towards ultrasensitive $\mathrm{H} 2 \mathrm{O} 2$ sensing. Electrochimica Acta 2017, 235, 471-479.

40. Zhang, Y.; Jiang, X.; Zhang, J.; Zhang, H.; Li, Y., Simultaneous voltammetric determination of acetaminophen and isoniazid using MXene modified screen-printed electrode. Biosensors and Bioelectronics 2019, 130, 315-321.

41. Shahzad, F.; Iqbal, A.; Zaidi, S. A.; Hwang, S.-W.; Koo, C. M., Nafion-stabilized twodimensional transition metal carbide (Ti3C2Tx MXene) as a high-performance electrochemical sensor for neurotransmitter. Journal of Industrial and Engineering Chemistry 2019, 79, 338-344.

42. Shankar, S. S.; Shereema, R. M.; Rakhi, R. B., Electrochemical Determination of Adrenaline Using MXene/Graphite Composite Paste Electrodes. ACS Applied Materials \& Interfaces 2018, 10 (50), 43343-43351.

43. Wu, D.; Wu, M.; Yang, J.; Zhang, H.; Xie, K.; Lin, C.-T.; Yu, A.; Yu, J.; Fu, L., Delaminated Ti3C2Tx (MXene) for electrochemical carbendazim sensing. Materials Letters 2019, 236, 412-415. 
44. Xie, Y.; Gao, F.; Tu, X.; Ma, X.; Xu, Q.; Dai, R.; Huang, X.; Yu, Y.; Lu, L., Facile Synthesis of MXene/Electrochemically Reduced Graphene Oxide Composites and Their Application for Electrochemical Sensing of Carbendazim. Journal of The Electrochemical Society 2019, 166 (16), B1673-B1680.

45. Tu, X.; Gao, F.; Ma, X.; Zou, J.; Yu, Y.; Li, M.; Qu, F.; Huang, X.; Lu, L., Mxene/carbon nanohorn/ $\beta$-cyclodextrin-Metal-organic frameworks as high-performance electrochemical sensing platform for sensitive detection of carbendazim pesticide. Journal of Hazardous Materials 2020, 396, 122776.

46. Lorencova, L.; Bertok, T.; Filip, J.; Jerigova, M.; Velic, D.; Kasak, P.; Mahmoud, K. A.; Tkac, J., Highly stable Ti3C2Tx (MXene)/Pt nanoparticles-modified glassy carbon electrode for $\mathrm{H} 2 \mathrm{O} 2$ and small molecules sensing applications. Sensors and Actuators B: Chemical 2018, 263, 360-368.

47. Vanysek, P., CRC Handbook of Chemistry and Physics. CRC Handbook of Chemistry and Physics 1998.

48. Zhao, F.; Yao, Y.; Jiang, C.; Shao, Y.; Barceló, D.; Ying, Y.; Ping, J., Self-reduction bimetallic nanoparticles on ultrathin MXene nanosheets as functional platform for pesticide sensing. Journal of Hazardous Materials 2020, 384, 121358.

49. Yao, Y.; Lan, L.; Liu, X.; Ying, Y.; Ping, J., Spontaneous growth and regulation of noble metal nanoparticles on flexible biomimetic MXene paper for bioelectronics. Biosensors and Bioelectronics 2020, 148, 111799.

50. Jiang, Y.; Zhang, X.; Pei, L.; Yue, S.; Ma, L.; Zhou, L.; Huang, Z.; He, Y.; Gao, J., Silver nanoparticles modified two-dimensional transition metal carbides as nanocarriers to fabricate acetycholinesterase-based electrochemical biosensor. Chemical Engineering Journal 2018, 339, 547556.

51. Filip, J.; Zavahir, S.; Lorencova, L.; Bertok, T.; Yousaf, A. B.; Mahmoud, K. A.; Tkac, J.; Kasak, P., Tailoring Electrocatalytic Properties of Pt Nanoparticles Grown on Ti3C2TXMXene Surface. Journal of The Electrochemical Society 2019, 166 (2), H54-H62.

52. Wang, J.; Liu, Y.; Yang, G., Cobalt decorated ultra-thin Ti3C2 MXene electrocatalyst for highefficiency hydrogen evolution reaction. Materials Research Express 2018, 6 (2), 025056.

53. Zhang, C.; Ma, B.; Zhou, Y.; Wang, C., Highly active and durable Pt/MXene nanocatalysts for ORR in both alkaline and acidic conditions. Journal of Electroanalytical Chemistry 2020, 865, 114142.

54. Filip, J.; Wechsler, P.; Stastny, J.; Malkova, V.; Minarik, A.; Vinter, S.; Osicka, J., Simplified synthesis of silver nanoparticles on graphene oxide and their applications in electrocatalysis. Nanotechnology 2020, 32 (2), 025502.

55. Karthik, R.; Govindasamy, M.; Chen, S.-M.; Mani, V.; Lou, B.-S.; Devasenathipathy, R.; Hou, Y.-S.; Elangovan, A., Green synthesized gold nanoparticles decorated graphene oxide for sensitive determination of chloramphenicol in milk, powdered milk, honey and eye drops. Journal of Colloid and Interface Science 2016, 475, 46-56.

56. Zhang, J.; Liu, H.; Wang, B.; Thabit, M.; Bai, H., Preparation of Pd/GO/Ti electrode and its electrochemical degradation for 2,4-dichlorophenol. Materials \& Design 2015, 86, 664-669.

57. Fu, L.; Wang, A.; Su, W.; Zheng, Y.; Liu, Z., A rapid electrochemical sensor fabricated using silver ions and graphene oxide. Ionics 2018, 24 (9), 2821-2827.

58. Ling, Z.; Ren, C. E.; Zhao, M. Q.; Yang, J.; Giammarco, J. M.; Qiu, J.; Barsoum, M. W.; Gogotsi, Y., Flexible and conductive MXene films and nanocomposites with high capacitance. (10916490 (Electronic)). 
59. Zou, G.; Zhang, Z.; Guo, J.; Liu, B.; Zhang, Q.; Fernandez, C.; Peng, Q., Synthesis of MXene/Ag Composites for Extraordinary Long Cycle Lifetime Lithium Storage at High Rates. ACS Applied Materials \& Interfaces 2016, 8 (34), 22280-22286.

60. Pandey, R. P.; Rasool, K.; Madhavan, V. E.; Aïssa, B.; Gogotsi, Y.; Mahmoud, K. A., Ultrahigh-flux and fouling-resistant membranes based on layered silver/MXene (Ti3C2TX) nanosheets. Journal of Materials Chemistry A 2018, 6 (8), 3522-3533.

61. Ferraria, A. M.; Carapeto, A. P.; Botelho do Rego, A. M., X-ray photoelectron spectroscopy: Silver salts revisited. Vacuum 2012, 86 (12), 1988-1991.

62. Satheeshkumar, E.; Makaryan, T.; Melikyan, A.; Minassian, H.; Gogotsi, Y.; Yoshimura, M., One-step Solution Processing of Ag, Au and Pd@MXene Hybrids for SERS. Scientific Reports 2016, 6 (1), 32049.

63. Li, H.; Du, Z., Preparation of a Highly Sensitive and Stretchable Strain Sensor of MXene/Silver Nanocomposite-Based Yarn and Wearable Applications. ACS Applied Materials \& Interfaces 2019, 11 (49), 45930-45938.

64. Pasricha, R.; Gupta, S.; Srivastava, A. K., A Facile and Novel Synthesis of Ag-Graphene-Based Nanocomposites. Small 2009, 5 (20), 2253-2259.

65. Vijay Kumar, S.; Huang, N. M.; Lim, H. N.; Marlinda, A. R.; Harrison, I.; Chia, C. H., Onestep size-controlled synthesis of functional graphene oxide/silver nanocomposites at room temperature. Chemical Engineering Journal 2013, 219, 217-224.

66. Evanoff, D. D.; Chumanov, G., Size-Controlled Synthesis of Nanoparticles. 2. Measurement of Extinction, Scattering, and Absorption Cross Sections. The Journal of Physical Chemistry B 2004, 108 (37), 13957-13962.

67. Mao, S.; Pu, H.; Chen, J., Graphene oxide and its reduction: modeling and experimental progress. RSC Advances 2012, 2 (7), 2643-2662.

68. Narayana, M. V.; Jammalamadaka, S. N., Tuning Optical Properties of Graphene Oxide under Compressive Strain Using Wet Ball Milling Method. Graphene 2016, Vol.05No.02, 8.

69. Dat, N. M.; Long, P. N. B.; Nhi, D. C. U.; Minh, N. N.; Duy, L. M.; Quan, L. N.; Nam, H. M.; Phong, M. T.; Hieu, N. H., Synthesis of silver/reduced graphene oxide for antibacterial activity and catalytic reduction of organic dyes. Synthetic Metals 2020, 260, 116260.

70. Martínez-Orozco, R. D.; Rosu, H. C.; Lee, S.-W.; Rodríguez-González, V., Understanding the adsorptive and photoactivity properties of Ag-graphene oxide nanocomposites. Journal of Hazardous Materials 2013, 263, 52-60.

71. Szabó, T.; Berkesi, O.; Forgó, P.; Josepovits, K.; Sanakis, Y.; Petridis, D.; Dékány, I., Evolution of Surface Functional Groups in a Series of Progressively Oxidized Graphite Oxides. Chemistry of Materials 2006, 18 (11), 2740-2749.

72. Sun H, B. Y. J. W. a. X. N., Sol. Energy Mater. Sol. Cells 2008, 92, 76.

73. Liu, J.; Shang, Y.; Zhu, Q.; Zhang, X.; Zheng, J., A voltammetric immunoassay for the carcinoembryonic antigen using silver(I)-terephthalate metal-organic frameworks containing gold nanoparticles as a signal probe. Microchimica Acta 2019, 186 (8), 509.

74. Lou, Z.; Xu, J.; Zhou, J.; Yang, K.; Cao, Z.; Li, Y.; Liu, Y.; Lou, L.; Xu, X., Insight into atomic $\mathrm{H}^{*}$ generation, $\mathrm{H} 2$ evolution, and cathode potential of $\mathrm{MnO} 2$ induced $\mathrm{Pd} / \mathrm{Ni}$ foam cathode for electrocatalytic hydrodechlorination. Chemical Engineering Journal 2019, 374, 211-220.

75. Elshafey, R.; Radi, A.-E., Electrochemical impedance sensor for herbicide alachlor based on imprinted polymer receptor. Journal of Electroanalytical Chemistry 2018, 813, 171-177. 
76. Salač, J.; Šopík, T.; Stloukal, P.; Janásová, N.; Jursík, M.; Koutný, M., Slow release formulation of herbicide metazachlor based on high molecular weight poly(lactic acid) submicro and microparticles. International Journal of Environmental Science and Technology 2019, 16 (10), 61356144.

77. Gaffney, J. S.; Marley, N. A.; Clark, S. B., Humic and Fulvic Acids and Organic Colloidal Materials in the Environment. In Humic and Fulvic Acids, American Chemical Society: 1996; Vol. 651, pp 2-16.

78. Bejger, R.; Mielnik, L.; Włodarczyk, M.; Nicia, P., Studying of the interaction between peat humic acids and metazachlor using spectroscopy methods. Journal of Soils and Sediments 2018, 18 (8), 2675-2681.

79. Scaglia, B.; Baglieri, A.; Tambone, F.; Gennari, M.; Adani, F., Chlorpyrifos-methyl solubilisation by humic acids used as bio-surfactants extracted from lignocelluloses and kitchen wastes. Chemosphere 2016, 159, 208-213. 
Figures:
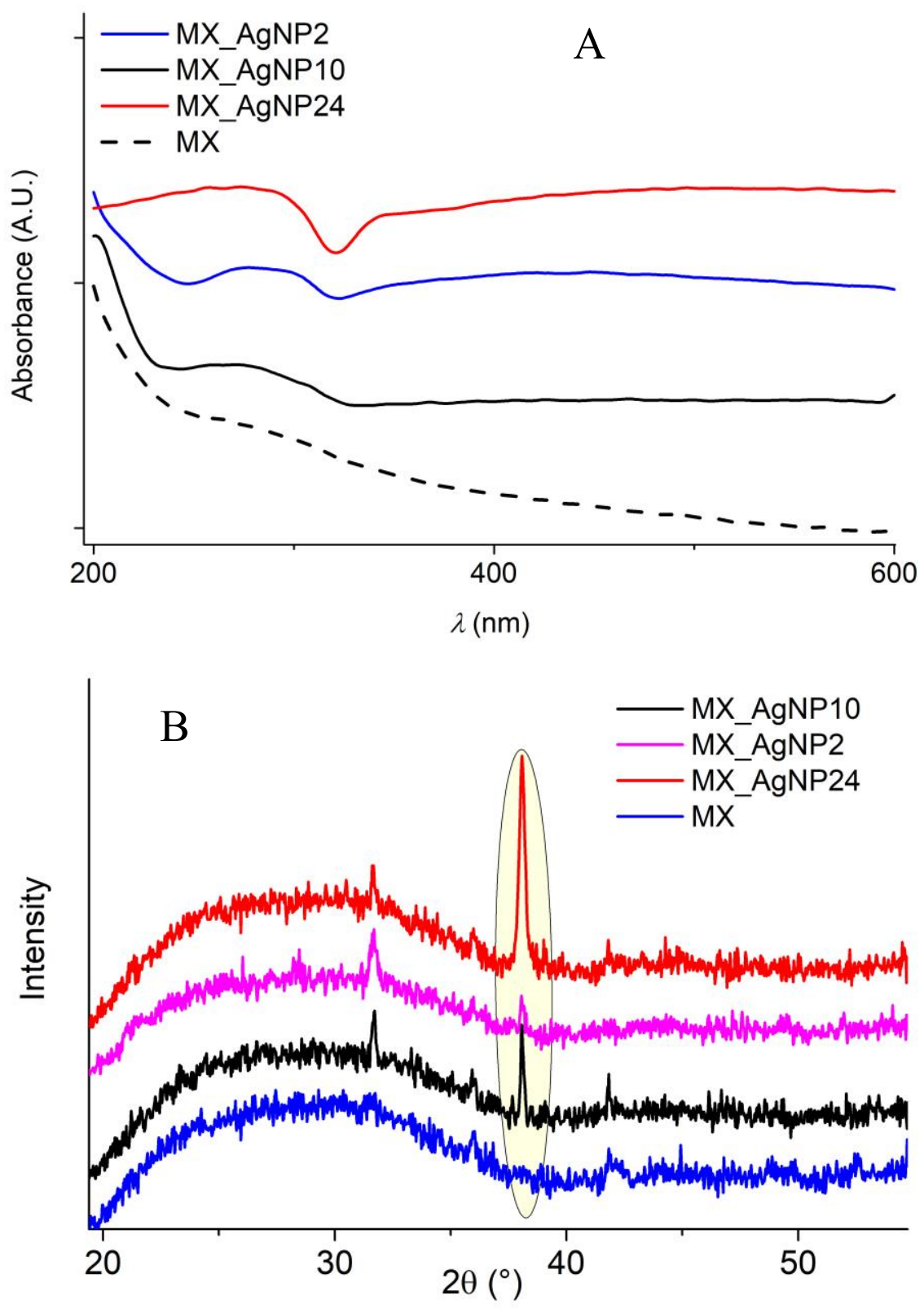

Figure 1: A - UV-VIS spectra of aqueous dispersions of MXene (black dashed), MX_AgNP10 (black), MX_AgNP2 (blue) and MX_AgNP24 (red). B - XRD data obtained from dry-deposited delaminated MXene (blue) and MX_AgNP10 (black), MX_AgNP2 (cyan) and MX_AgNP24 (red). Peaks related to Ag nanoparticles are marked in the yellow oval. 

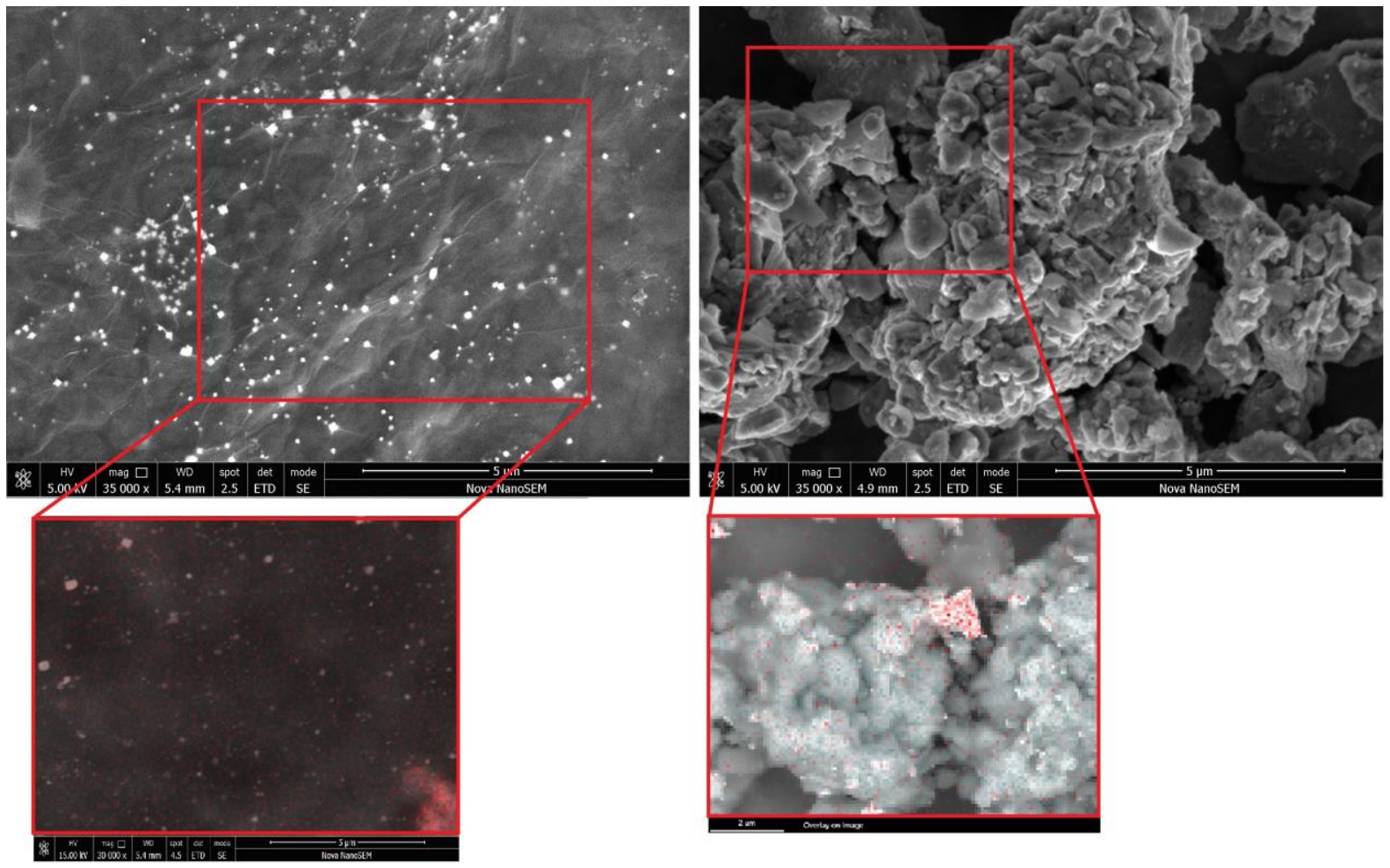

Figure 2: SEM images of GO_AgNP (left) and MX_AgNP (right) nanohybrids with scale bars of $5 \mu \mathrm{m}$ length indicated in the figures. Respective images bellow the SEM are results of the color mapping of areas marked by red rectangles. Red color designates EDAX signal of silver, green color is for titanium. 

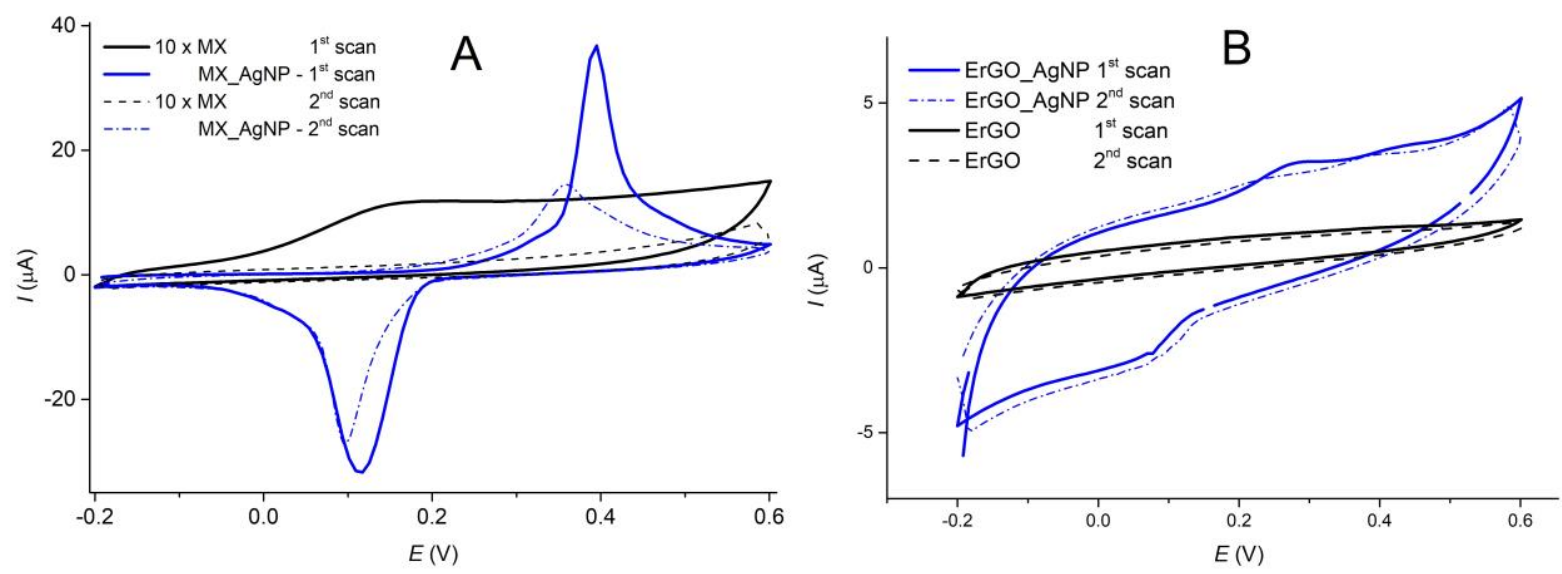

Figure 3: A - Cyclic voltammograms of GCE coated with MXene (black) and MX_AgNP (blue). First (thick solid) and second (thin dashed) CV scans are shown. Note that CVs for MXene are $\mathbf{1 0}$ fold zoomed to highlight the difference. B - cyclic voltammograms of GCE coated with ErGO (black curves) and ErGO_AgNP (blue curves). First (thick solid) and second (thin dashed) CV scans are shown. 

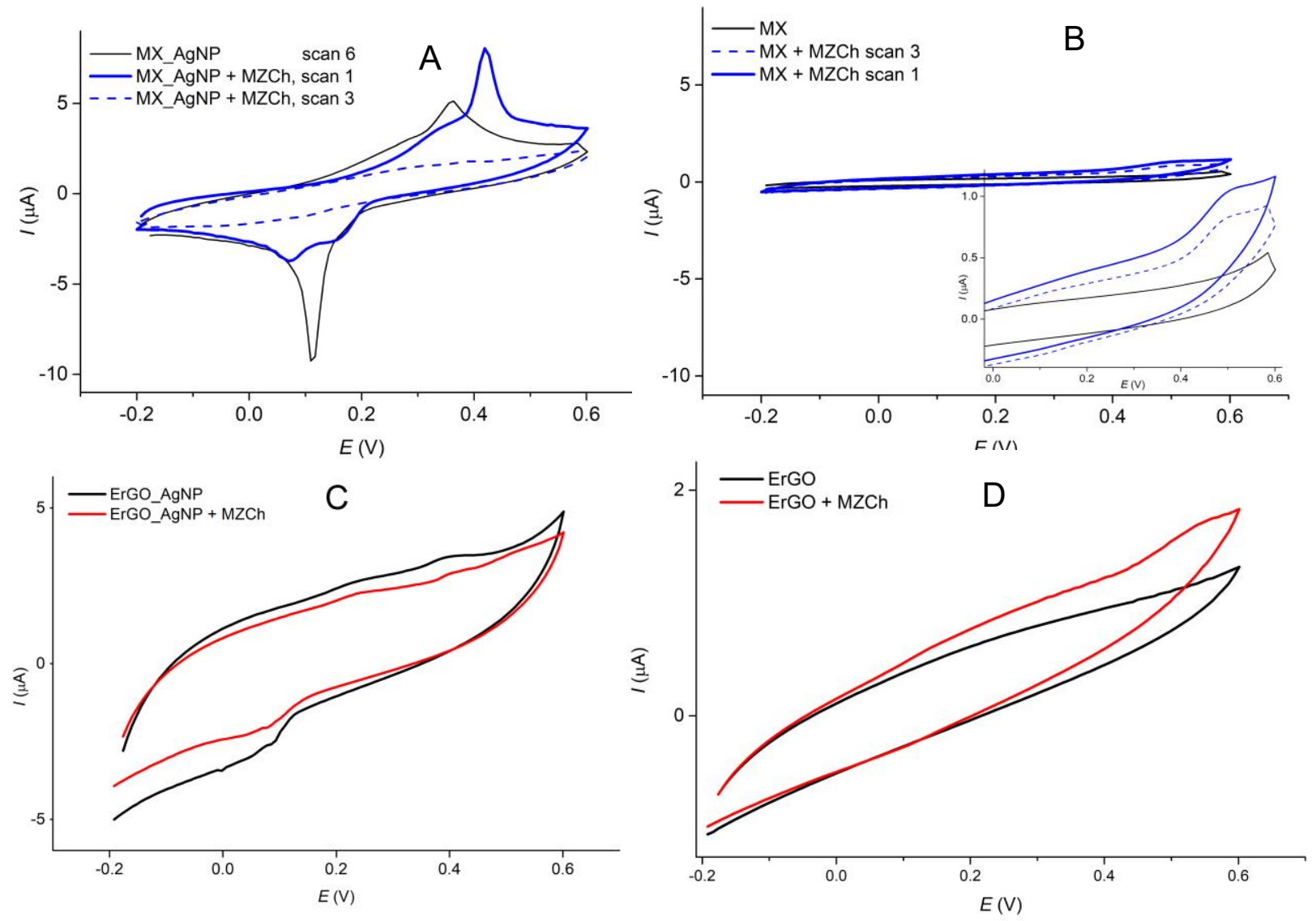

Figure 4: CV voltammograms of GCEs modified by MX_AgNP24 (A) MXene (B) in $20 \mathrm{mM} \mathrm{NaOH}$ alone (black curves) and with $1.12 \mathrm{mM} \mathrm{MZCh}$ (blue curves). For the former case first (solid line) and third scans (dashed lines) are shown. Inset in panel B - enlarged part of CVs voltammograms. Bottom graphs CV voltammograms of GCEs modified by ErGO_AgNP (C) and ErGO (D) in $20 \mathrm{mM} \mathrm{NaOH}$ alone (black curves) and with $1.12 \mathrm{mM}$ MZCh (red curves). 

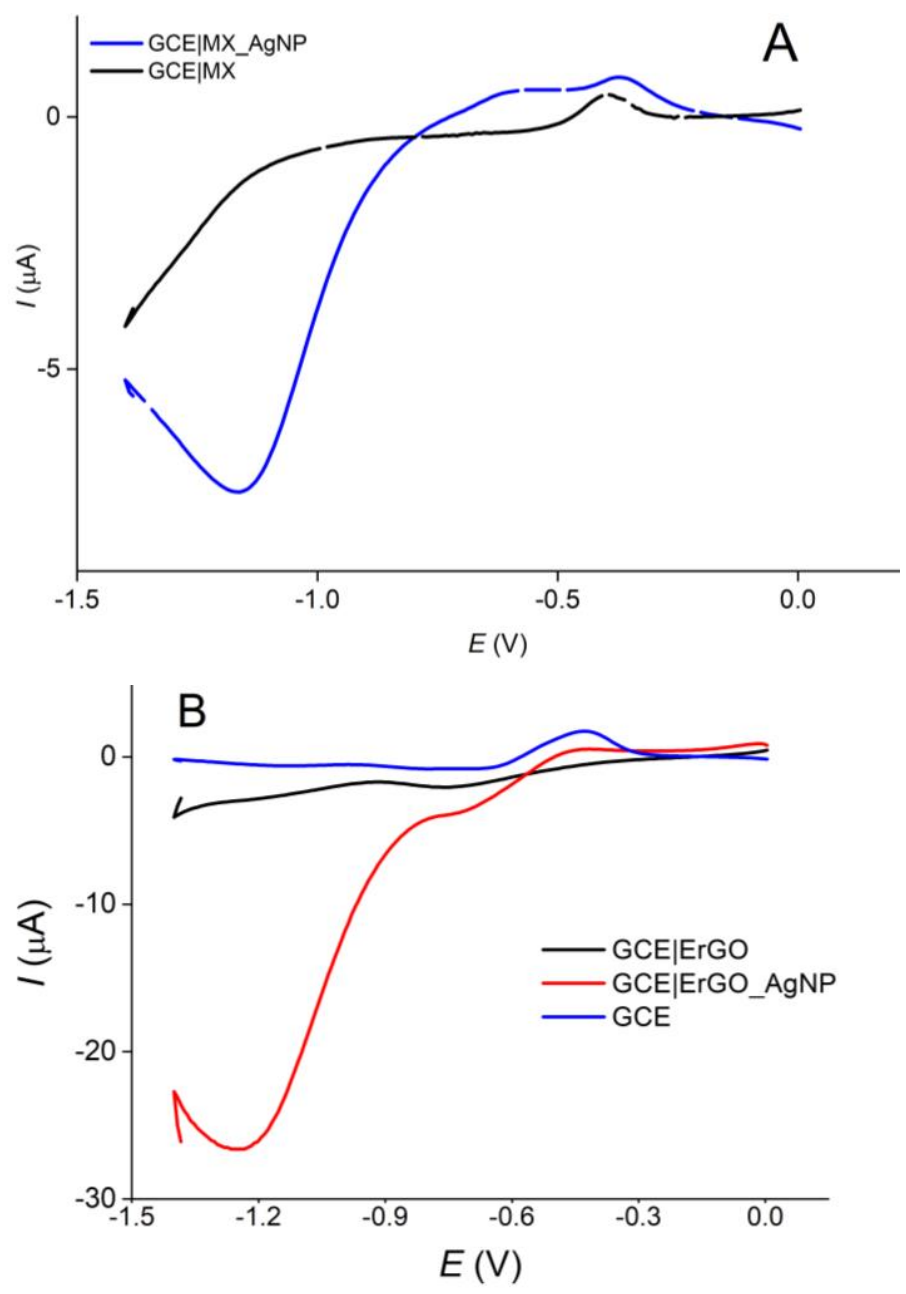

Figure 5: A) Cathodic parts of background-corrected voltammograms achieved by GCEs modified by MX (black) and MX_AgNP (blue) in a quiescent $50 \mathrm{mM} \mathrm{NaOH}$ solution containing $320 \mathrm{mg} . \mathrm{L}^{-1}(1.15 \mathrm{mM})$ metazachlor. A) Cathodic parts of background-corrected voltammograms achieved by an unmodified GCE (blue), GCEs modified by ErGO (black), and ErGO_AgNP (red) in a quiescent $50 \mathrm{mM} \mathrm{NaOH}$ solution containing $320 \mathrm{mg} \cdot \mathrm{L}^{-1}(1.15 \mathrm{mM})$ metazachlor. All scan rates are $50 \mathrm{mV} \mathrm{s}^{-1}$. 

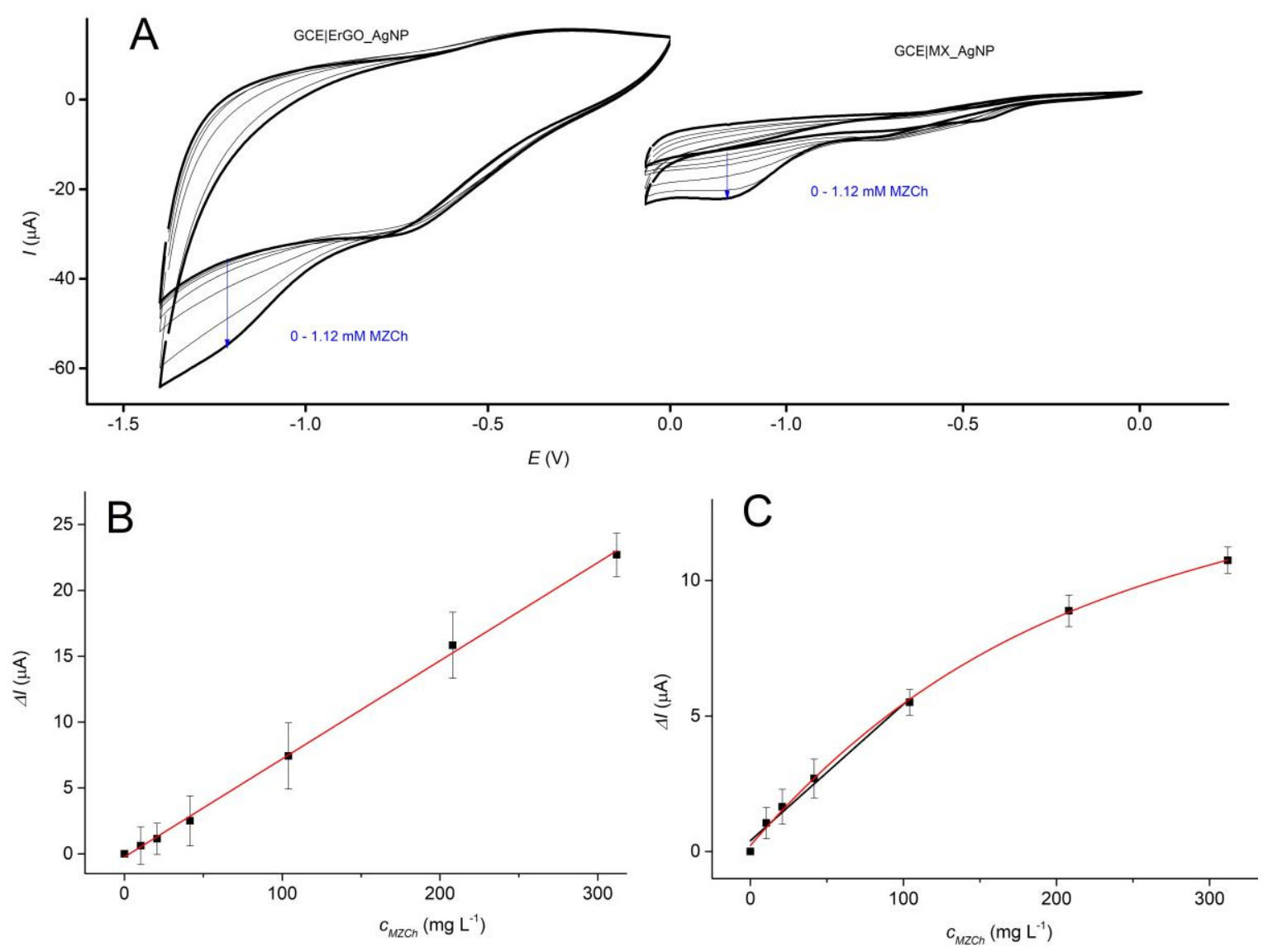

Figure 6: $\mathbf{A}-\mathrm{CV}$ s achieved with GCEs modified with ErGO_AgNP and MX_AgNP (indicated in the figure) in presence of $0-1.12 \mathrm{mM} \mathrm{MZCh} . \mathbf{B}, \mathbf{C}$ - calibration curves obtained with electrodes GCE|ErGO_AgNP (B) and GCE|MX_AgNP (C) using linear (red line in $\mathbf{B}$ and black line in $\mathbf{C}$ ) or cubic (red curve in $\mathbf{C}$ ) fitting of the obtained values (black points). 


\section{Tables:}

Table 1: the measured concentrations in leachates of the soil with added metazachlor (lines "real") and in the leachates with metazachlor added after the leaching procedure (net concentration of $50 \mathrm{mg} \mathrm{L}^{-1}$ in the measured solution), lines "added". All values are expressed as percentage of the expected values, that is, $c_{m} / c_{t} \times 100(\%)$ where $c_{m}$ is the measured concentration and $c_{t}$ is the theoretical concentration calculated from the known concentrations and the measured calibration curves.

\begin{tabular}{|c|l|l|l|}
\hline \multirow{2}{*}{ Sample } & \multicolumn{2}{|l|}{ \% of the expected concentrations } \\
\cline { 2 - 4 } & GCE|MX_AgNP & GCE|ErGO_AgNP \\
\hline \multirow{2}{*}{ F } & real & $23.4 \pm 8.8$ & $241 \pm 10$ \\
\cline { 2 - 4 } & added & $17.4 \pm 5.5$ & $108 \pm 14$ \\
\hline \multirow{2}{*}{ P } & real & $60.9 \pm 11.3$ & $248 \pm 52$ \\
\cline { 2 - 4 } & added & $30.2 \pm 7.1$ & $110 \pm 7$ \\
\hline
\end{tabular}

